\title{
Estimating the Impact of Structural Reforms to Increase the Female Participation Rate in Malta
}

\author{
Brian Micallef ${ }^{1}$ \\ ${ }^{1}$ Manager, Research Office, Central Bank of Malta, Malta \\ Correspondence: Brian Micallef, Research Office, Central Bank of Malta, Castille Place, Valletta, Malta.
}

Received: July 17, 2018

doi:10.11114/ijsss.v6i8.3495
Accepted: July 24, 2018 Available online: July 31, 2018

URL: https://doi.org/10.11114/ijsss.v6i8.3495

\begin{abstract}
Malta registered the largest increase in the female participation rate among European countries since 2008. This increase was driven by various policy initiatives aimed to attract more females to the labour market but also by the changing role of women in society. Furthermore, at $53.8 \%$ in 2015, the female participation rate in Malta still remains relatively low by European standards, suggesting further catching-up potential. The trend increase in participation, driven mostly by females, is estimated to have contributed, on average, to 0.8 percentage points per annum to Malta's potential GDP between 2008 and 2015. The impact of reforms is calculated by adjusting the post-2008 participation rate to long run trends in Maltese society, as well as using a cohort model that accounts for the changing demographics and education attainment of the workforce. The median impact of the estimates presented in this paper suggests that around half of the increase in the female participation rate is attributable to reforms. These reforms are estimated to have raised potential GDP growth in Malta by around 0.3 percentage point per annum between 2008 and 2015.
\end{abstract}

\section{JEL classification: E24, J11, J21, J24}

Keywords: structural reforms, labour market, female participation rate, Malta

\section{Introduction}

Due to cultural and historical factors, the Maltese economy, a small island in the Mediterranean and the smallest member of the euro area, has always had one of the lowest female participation rates in Europe. In the mid-1980s, Malta's female participation rate stood around $29 \%$ and only increased to $36 \%$ by 2005 compared to $63 \%$ in the EU.

Things started to improve in the late 2000s. The Maltese government introduced a number of reforms to address the objectives of the Europe 2020 Strategy, including raising the female participation rate. The female participation rate in Malta increased by 13.4 percentage points between 2008 and 2015, by far the largest increase among EU countries. Furthermore, at 53.8\% in 2015, it still remains relatively low by European standards, suggesting further catching-up potential (see figure 1). Policy initiatives as well as other structural factors, such as higher education, lower fertility, changes in social norms and the introduction of more flexible work practices contributed to the increase in the female participation rate.

Existing studies, mostly based on general equilibrium models, suggest that Malta would benefit from a package of labour market reforms. Varga and int'Veld (2014) estimate that a reform package covering both the product and labour market in which Malta reduces the existing gap compared to the three best performing EU member states by half raises GDP of 7.6\% relative to its no-reform baseline over a decade. The greatest gains are those that raise the skills of the workforce and efforts to increase the participation rate of females and older workers. Micallef (2013) estimates that labour market reforms have a more pronounced impact in Malta compared to product market ones. Similarly, estimates presented in the National Reform Programme for 2015 suggest that the various labour market reforms undertaken in recent years are expected to raise GDP and employment by $2.8 \%$ and $4.6 \%$, respectively, by 2020 relative to $2014{ }^{1}$

\footnotetext{
${ }^{1}$ Ministry of Finance (2015)
} 


\section{Female participation rate in EU countries}

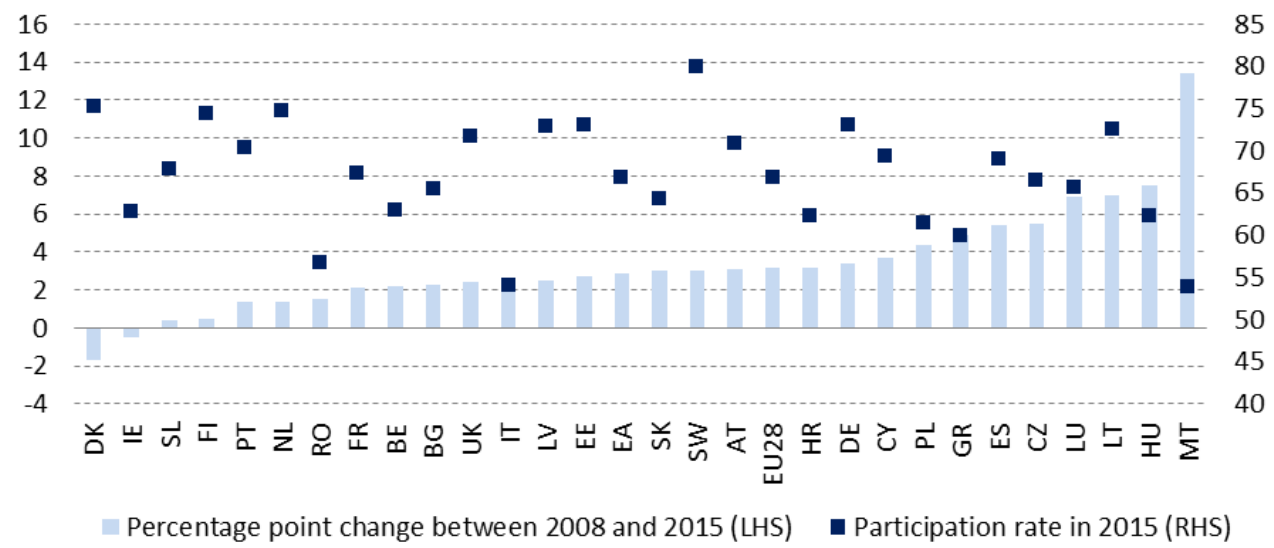

Figure 1. Participation rate in EU countries in 2015

This paper estimates the impact of structural reforms to raise the female participation rate on Malta's potential GDP. Potential GDP growth is calculated using constant returns to scale Cobb-Douglas production function, with the labour input further decomposed into the effects of the working-age population, the trend participation rate, trend hours worked and the structural unemployment rate. Two different approaches are used to adjust the increase in the female participation rate. The first methods adjusts the working-age population and the supply of labour after 2008 to account for labour market trends that would have occurred irrespective of the reforms, such as the ageing population and the changing role of women in society. The second method is based on a cohort model of labour participation to focus on the importance of compositional changes in the female participation rate, both in terms of demographics and educational attainment.

The main findings are the following. The increase in the trend participation rate is estimated to have raised potential GDP by 0.8 percentage points per annum between 2008 and 2015. The median estimate of the two main approaches used suggests that slightly less than half of increase in the female participation rate between 2008 and 2015 is attributable to labour market reforms. Overall, the impact of the later is calculated to have raised Malta's potential GDP growth by 0.3 percentage points per annum since 2008 .

The rest of this paper is structured as follows. Section 2 presents a brief literature review of the main factors affecting women's labour supply decisions. Section 3 discusses the Maltese labour market and the main reforms undertaken to raise the female participation rate. Section 4 estimates the contribution of the labour input to potential GDP growth in Malta using a production function approach while Section 5 estimates the contribution of the reforms on Malta's potential GDP growth. Section 6 concludes.

\section{Brief Literature Review}

According to Becker's time allocation model, women make a choice between working at home or joining the labour force and earn a market wage (Becker, 1965). Within this framework, the labour supply of females is affected both by individual characteristics and government policies.

Individual or demographic factors play an important role in females' employment decisions. Women's marital status and the number of children tend to be associated with lower participation rates. Christiansen et al (2016) find that while marriage in itself does not significantly alter women's decision to join the labour force, married women tend to work shorter hours compared to unmarried ones. These authors also report that adding one child to the household is associated with a six percentage point reduction in the likelihood of women working. The participation rate of women also varies over the life-cycle and it usually dips in the child-rearing ages between mid-20s to mid-30s.

Better educated females are more likely to join the labour market since education raises their potential earnings relative to household work (Eckstein and Lifshitz, 2011). Pissarides et al (2005) report that the employment rate of highly educated women in Europe is higher than those with a lower level of education, with the former also exhibiting a smaller gender gap in employment.

Gender attitudes or social beliefs about women's role in society can also influence the decision on whether or not to participate in the labour market. Fernandez (2013) attributes the increase in the female participation rate in the US over the last century to the dramatic change in social attitudes towards married women working. It is also likely that such attitudes evolve over time such that the exposure to working women or to females in leadership positions can weaken 
gender stereotypes, thereby helping to raise the participation rate in future generation of females. Furthermore, women who grow up with working mothers are more likely to join the labour force as adults (McGinn et al, 2015).

Structural changes in the economy and technology can also influence the decisions of females to join the labour force. Albanesi and Olivetti (2009) argue that medical progress and technological change (e.g. the introduction of infant formula that reduced the comparative advantage of mothers in infant feeding) helped to reconcile work and motherhood and therefore, facilitated the entry of married women in the labour force. Thévenon (2013) claims that the expansion of the services sector has increased the demand for work in which females have a comparative advantage, thus drawing more women in the labour market.

In addition to structural or individual characteristics, government policies can play an important role on women's decision to join the labour force. Tax systems or legislation that discriminates against married women can distort women's labour supply decisions by reducing the return to market work. Keane (2011) finds that the labour supply of females is quite sensitive to taxation. The tax treatment of married couples (e.g. joint or separate taxation) that reduce the disincentive of the second wage earner are associated with a higher female participation rates (Bick and Fuchs-Schündeln, 2014).

Policies that help women to bridge the gap between family and work balance could support females to join the labour market. Such policies include flexible work practices, such as part-time work or teleworking, maternity leave and improved access to complementary services, such as child and elderly care (Jaumotte, 2003; Edin and Gustavasson, 2008; Steinberg and Nakane, 2012; Thévenon, 2013). Part-time employment facilitates women's integration in the labour market and is generally positively correlated with the female employment rate. In some instances, however, part-time employment is involuntary, possible due to policy-induced constraints in assuming a full-time job, such as taxation or the under provision of child-care. Thévenon (2013) finds that childcare support, such as childcare subsidies and the provision of public childcare, has helped to raise the female participation rate in OECD countries. On the contrary, high lump-sum or benefit cash transfers that raise the non-wage household income can lower the necessity of females to return to the labour market. Similarly, excessive parental leave could actually hurt women's decision to re-enter the labour market due to a deterioration of market skills (Edin and Gustavasson, 2008). Christiansen et al (2016) find an inverted U-shaped relationship between the number of weeks of parental leave and the likelihood of female employment, which calls for careful design of parental leave.

Using individual level data from different rounds of the International Social Survey Programme (ISSP) across 24 European countries, Christiansen et al (2016) find that both personal choices and policies matter for females' labour supply decisions. Higher education, lower birth rates, changing social norms and exposure to working mothers are important drivers of women's decision to join the labour force. On their own, however, these factors cannot fully explain the participation rate of females in Europe. In terms of policies, the tax treatment of the second wage earner and the provision of services that facilitates the combination of work with household and care responsibilities play an important role in supporting the return of females to the labour market.

\section{Labour Market Developments in Malta}

Due to a number of cultural factors, Malta has always had a low female participation rate by European standards. According to Darmanin (2003), various restrictions in place until the late 1970s have favoured men at the expense of women in the Maltese labour market. For instance, women were obliged to give up employment upon marriage, restrictions were in place that required positions occupied by males to be filled again by males and there were no legal restrictions on wage differentials among genders for the same job. Malta's female participation rate stood around $29 \%$ in the mid-1980s and only increased to $36 \%$ by 2005 compared to $63 \%$ in the EU.

EU membership in 2004 facilitated the diversification of the Maltese economy's productive base towards higher-value added activities, mostly in the services sector (Grech et al, 2016). The labour market also kept the pace with the rapid evolution of the economy and was very resilient after the crisis, with Malta registering one of the highest growth rates in employment among the EU countries (Micallef, 2013).

Focusing on more recent development, employment in Malta increased by 24,500 persons between 2008 and 2015, mostly due to females (see Table 1). Full-time jobs accounted for around two thirds of the increase in employment. Females accounted for around $80 \%$ of the increase in full-time employment and to $70 \%$ of part-time employment. In terms of full-time employment, around two thirds of the new jobs for females were created in public administration, education, healthcare \& social work activities. In part, this is associated with the structural changes that occurred in the Maltese economy, with activities previously conducted informally by housekeepers now being serviced by the formal economy, such as residential care (Grech, 2015b). Around $17 \%$ of full-time employment for women was created in professional, technical, administrative and support services activities, while another $10 \%$ in the wholesale and retail sector. The latter sector accounted for slightly less than $30 \%$ of the new part-time jobs for females. 
Table 1. Employment decomposition by Gender and Job Contract

\begin{tabular}{crr}
\hline & $1000 \mathrm{~s}$ & $\%$ \\
\hline Difference in employment between 2008 and 2015 & 24,500 & 15.5 \\
Males & 5,900 & 5.6 \\
Females & 18,500 & 35.1 \\
Due to full-time & 15,500 & 11.1 \\
Males & 3,300 & 3.3 \\
Females & 12,300 & 31.1 \\
Due to part-time & 8,900 & 50.9 \\
Males & 2,700 & 62.8 \\
Females & 6,300 & 47.7 \\
\hline
\end{tabular}

Source: Labour Force Survey, Eurostat

The increase in female employment was facilitated by a number of government initiatives aimed at increasing the participation rate of women in the labour market. Measures include back-to-work fiscal incentives for women, new income tax computations, an increase in maternity and adoption leave, tax credits for self-employed and exemptions of means-testing for income earned by women working part-time. Self-employed women working on a part time basis, as in the case of employed persons, were given the opportunity to choose to pay a 15\% pro rata contribution on their income. An In-Work Benefit was introduced and subsequently extended to top up the income for single-earner households while the structure of the benefit retains a strong incentive for the second earner to enter into employment (Bugeja et al, 2016).

Childcare facilities were made more available and affordable. A number of public child care centres were introduced and their operational hours extended until $16.00 \mathrm{hrs}$ to be more effective for working parents. After-school care services were also introduced in a number of schools to bridge the gap between day school and regular working hours of parents in employment. For instance, the 'Klabb 3-16' has been in operation since 2009 and provides after-school service to children whose parents are in employment. This service operates throughout the scholastic year and school holidays, including summer. Other initiatives were targeted to provide care for children before schools' official opening hours, thus allowing more flexibility to working parents. For instance, the so-called 'Breakfast Club' caters for children attending public schools before the schools' official opening hours (between 07.30 and 08.30). This initiative is open to every primary public school in Malta and Gozo.

In conjunction with the above initiatives, a number of measures were aimed to further improve basic skills attainment and reduce early school leavers, both of which intended to strengthen the employability prospects of people joining the labour market.

\section{Female participation rate by cohort}

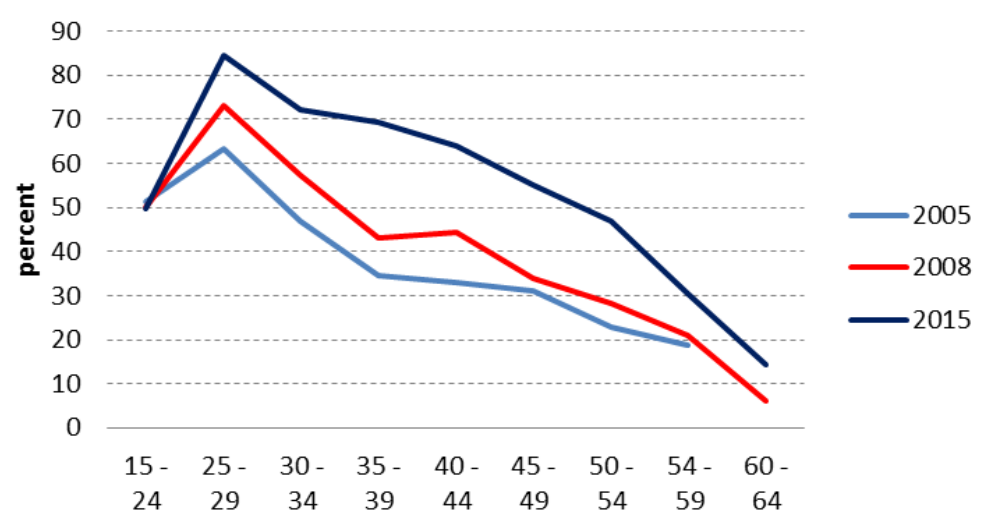

Figure 2. Female participation rate in Malta by cohort over time

In addition to the number of government initiatives aimed at attracting more women to the labour force, the increased female participation rate is also related to the transformation in the role of women in society, with rising education levels combined with changing social norms (Grech, 2015). Figure 2 plots the evolution of the female participation rate by cohort over the last decade. Historically, the female participation rate in Malta tended to peak in the early 20 s and decrease sharply thereafter as women dropped out of the labour force completely after child birth. More recently, however, the female participation rate started to peak in the late $20 \mathrm{~s}$ and, after the dip in later years due to the child-bearing effects, remain much higher compared to a decade ago. This could reflect easier access to child care, as well as the impact of higher education attainment levels, which generally lead to a quicker return to work after childbirth. Changes in labour 
force participation could also be influenced by developments in the housing market. The rise in house prices and, more generally, the increase in household indebtedness may have both reflected and reinforced the trend towards higher female participation rates.

The increase in the female participation rate helped to narrow the gender gap in Malta although it still remains the largest in the EU. In 2015, the gender gap in the 25 to 59 age bracket stood at more than 33 percentage points in Malta, a decline of more than 14 percentage points compared to 2008 but far higher than the EU average of 12.4 percentage points. The gender gap varies across education levels and age groups. The gender gap in Malta is most prevalent in older people and those with a low level of education. On the contrary, the gender gap for those with a tertiary level of education is lower than that prevailing in the EU.

Similar differences are also observed in the female participation rate between Malta and the EU (see figure 3). Malta's participation rate in the 15-24 age bracket is substantially higher than that observed in the EU, while that of the older categories is significantly lower. In terms of educational attainment, most of the differences are concentrated in the lowest education category, which covers primary and lower secondary. Indeed, within the 25-49 age bracket, the female participation rate in Malta in the medium and high education category is higher than the EU average.

\section{Female participation rate by age and education attainment (2015)}

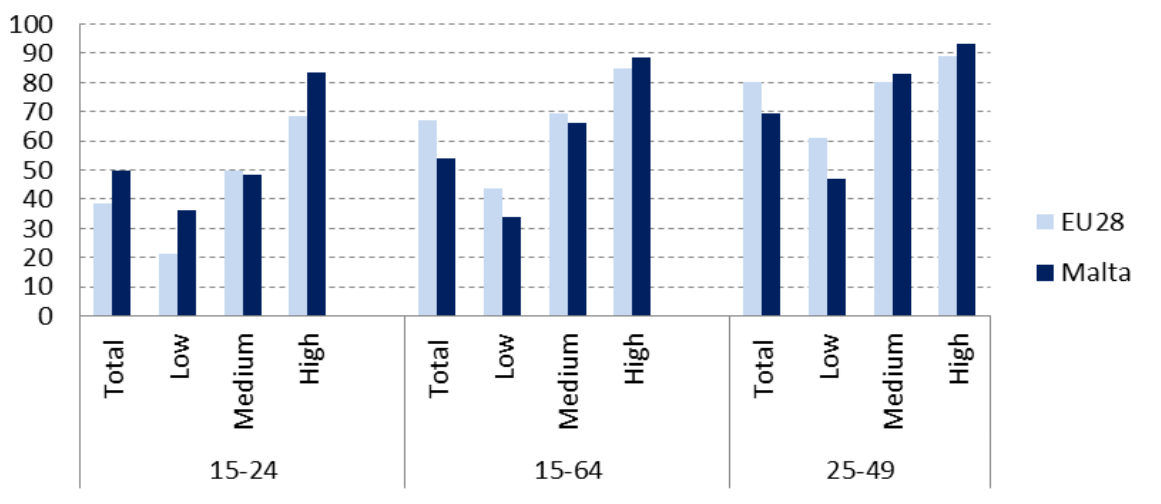

Figure 3. Female participation rate in Malta and EU by age and education attainment

\section{The Impact of the Participation Rate on Potential GDP Growth}

The impact of changes in the participation rate on potential output is calculated using a production function to model the supply-side of the Maltese economy for the period 1985-2015. Following Grech and Micallef (2016), the production function consists of a constant-returns-to-scale Cobb-Douglas specification, namely:

$$
\mathrm{Y}_{\mathrm{t}}=\mathrm{TFP}_{\mathrm{t}} \mathrm{K}_{\mathrm{t}}^{\alpha} \mathrm{L}_{\mathrm{t}}^{1-\alpha}
$$

where $\mathrm{Y}_{\mathrm{t}}$ denotes output at time $\mathrm{t}, \mathrm{L}_{\mathrm{t}}$ the labour input in hours worked, $\mathrm{K}_{\mathrm{t}}$ the capital stock and $\mathrm{TFP}_{\mathrm{t}}$ the total factor productivity. ${ }^{2}$ The share of labour income is calibrated at 0.55 based on the share of compensation of employees in gross value added (GVA) adjusted for the proportion of the labour force that consists of self-employed.

The trend labour input in hours worked can be further decomposed in four components:

$$
\mathrm{L}_{\mathrm{t}}=\mathrm{WAP}_{\mathrm{t}} \overline{\mathrm{PR}_{\mathrm{t}}}\left(1-\overline{\mathrm{UNR}_{\mathrm{t}}}\right) \overline{\mathrm{HRS}_{\mathrm{t}}}
$$

where $\mathrm{WAP}_{\mathrm{t}}$ denotes the working-age population, $\overline{P R_{t}}$ the trend participation rate, $\overline{\mathrm{HRS}_{\mathrm{t}}}$ the trend hours worked and $\overline{U N R_{t}}$ the structural unemployment rate or NAIRU. To help derive potential labour utilisation, the trend participation rate, hours worked and NAIRU are obtained using the HP filter.

Figure 4 plots the contribution of labour, capital and TFP to potential output growth between 1985 and 2015. The chart points to substantial changes in potential output growth during this period, with a trend decline in potential output from above $6 \%$ in the late 1980 s and early 1990s until reaching a trough of less than $2 \%$ in 2009 s. The slowdown in early $2000 \mathrm{~s}$ is attributable to both demand and supply side elements, with the cyclical upswing between 2005 and 2008 being

\footnotetext{
${ }^{2}$ TFP is derived as the HP-filter of the Solow residual, using the standard smoothing parameter of 100 for annual data.
} 
interrupted by the Great Recession of 2009. ${ }^{3}$ However, contrary to the experience in other countries, potential output in Malta has recovered after the crisis, with this growth being also reflected in the economy's supply potential. Estimates of potential GDP growth exceeded $6 \%$ in 2015, pushing the growth rate to levels last seen in the early 1990s.

\section{Decomposition of potential GDP growth}

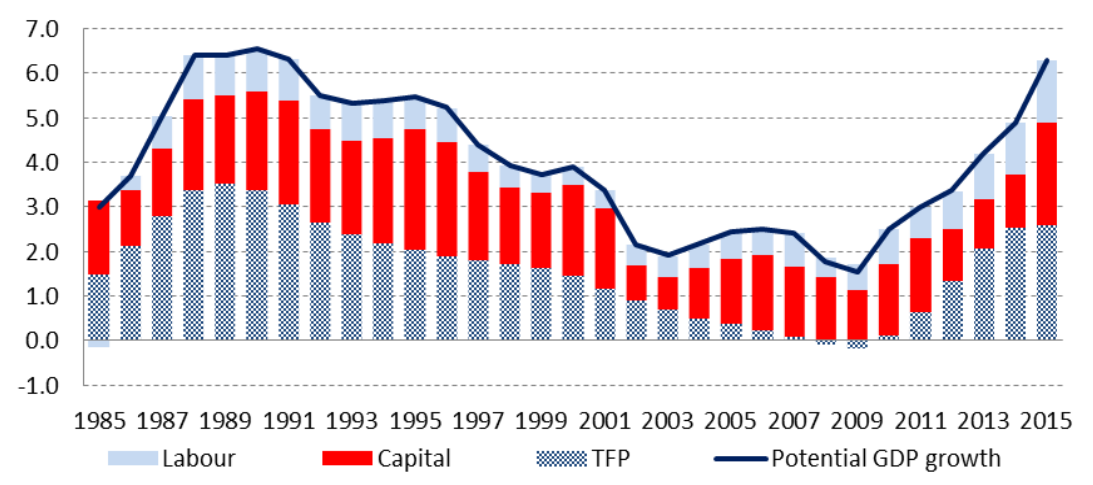

Figure 4. Potential GDP growth in Malta

Figure 5 decomposes the contribution of labour to potential output growth. From the mid-1980s until the Great Recession, the increase in the working-age population was the main driver of the trend labour supply. Since 2009, however, the unfavourable effects of an ageing population started to weigh in, with a gradual decline in the contribution of the working-age population. The impact of an ageing population have been mitigated in recent years by an inflow of foreign labour, the share of which increased from 1.7\% of the workforce in 2000 to 13.6\% in 2015 (Grech, 2014).

Growth in labour input since 2008 was driven by the rising participation rate. Higher participation has contributed, on average, to 0.8 percentage points per annum to potential GDP growth between 2008 and 2015. This was mainly driven by the increase in the female participation rate, which went up by 13.4 percentage points during this period, by far the largest increase among EU countries. Albeit to a much lesser extent, developments in NAIRU have also contributed positively to potential output growth after the crisis as the unemployment rate decline to historical lows by 2015 (Micallef, 2016). On the contrary, the trend decline in hours worked, which a common phenomenon observed in most European countries, contributed negatively to potential GDP growth (Blanchard, 2004). The decline in the average weekly hours worked reflects the increase in part-time work and other flexible work arrangements, such as family friendly measures, that are intended to attract more females in the labour market. The increase in part-time employment is also related to demographic trends, with older workers being more likely to engage in part-time work.

\section{Decomposition of the labour contribution}

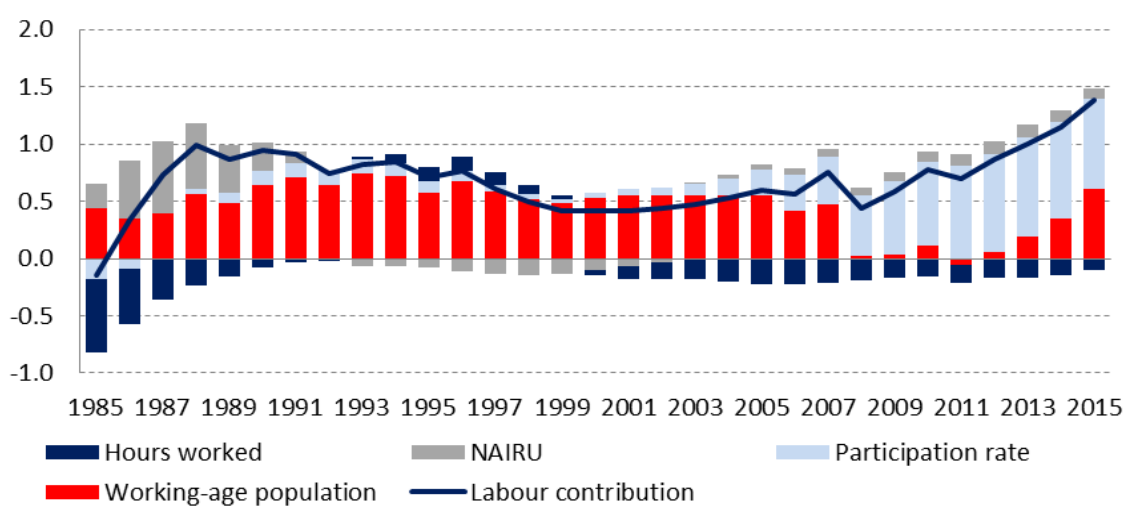

Figure 5. The contribution of labour input to potential GDP growth in Malta

\section{Assessing the Impact of Reforms on the Participation Rate}

The increase in the female participation rate masks the effects of factors unrelated to labour market reforms. After all,

\footnotetext{
${ }^{3}$ See Grech and Micallef (2014) for a detailed description of the main developments in Malta's potential output.
} 
besides labour market reforms, the labour force participation of women is determined by individual and structural characteristics (Christiansen et al, 2016).

This section aims to identify the effects of reforms by adjusting the increase in the participation rate using two different approaches. In the first method, adjustments are made to the headline participation rate to account for the decline in the working-age population that took place after 2008 and the trend increase in the labour supply that would have occurred irrespective of the reforms. The second method is based on a cohort model of labour participation to focus on the importance of compositional changes in the female participation rate, both in terms of demographics and educational attainment.

Besides these two methods, another common approach used in the literature to study the impact of reforms is to use difference-in-differences (DID) estimator. The latter method is used to identify the impact of policy changes where only part of the population is affected by the change in policy. In this case, the population is divided in two categories, the treatment group (affected by policy) and the control group (not affected). The key identifying assumption in DID is that trends for both the treatment and control groups would have been the same in the absence of a change in policy (Card and Krueger, 1994). However, an application of DID for Malta is particularly challenging. Identifying an appropriate control group is difficult as the various initiatives targeted women in all age brackets while the reforms were staggered over a number of years. Furthermore, the trends in the participation rate of males and females went into different direction before the crisis. Due to these challenges, DID estimation was not deemed appropriate for Malta.

\subsection{Aggregate Approach}

There are at least two factors that could have impacted positively the female participation rate in Malta in recent years in addition to government reforms. The first relates to the decline in the working age population. With the participation rate defined as the ratio of the labour force to the working-age population, a decline in the denominator would automatically increase the participation rate. The second factor relates to changes in the role of women in society. The decision to join the labour force is determined by a number of factors in addition to government policy. For instance, women finishing tertiary education will join the labour force irrespective of government incentives to attract more women back in employment.

Exhibit 6 plots the evolution of the labour supply and the working-age population of females between 1985 and 2015. The first chart shows the actual labour supply together with a hypothetical supply, based on a fitted linear trend between 1985 and 2007, which is extended over the period between 2008 and 2015. The fitted trend based on pre-2008 data is intended to proxy the trend increase in the females' labour supply that would have occurred irrespective of the labour market reforms. The chart however clearly shows that the increase in female labour supply post-2008 has by far outpaced the fitted trend line based on pre-2008 trend.

The second chart shows that the impact of an ageing population kicked-in around 2009-2010, with a sharp decline in the growth rate of the working-age population. A decline in the working-age population could bias upward the impact of reforms on the participation rate. To adjust for this effect, it is assumed that, hypothetically, the working-age population increases by $0.88 \%$ per annum between 2008 and 2015, its average growth over the period 1985-2007. According to this assumption, the working-age population of females would have increased to around 149,000 in 2015 instead of declining to 139,700 .

Adjusting for these two effects would lower the female participation rate by 4.3 percentage points in 2015 , from $53.8 \%$ to $49.5 \%$. This implies that out of the 13.4 percentage point increase in the female participation rate since 2008, around one-fourth could not be explained by the decline in the working-age population and the natural increases in the labour supply of females and hence, could be attributable to labour market reforms. 


\section{Labour supply of females}

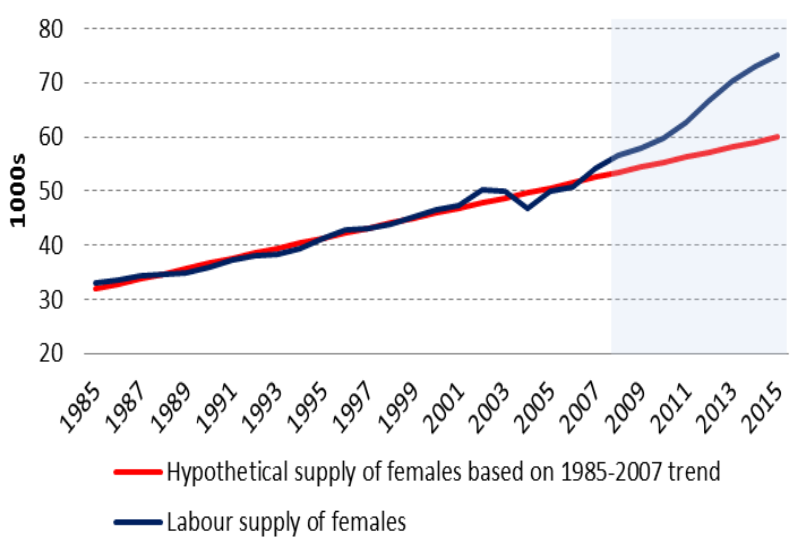

\section{Working-age population of females}

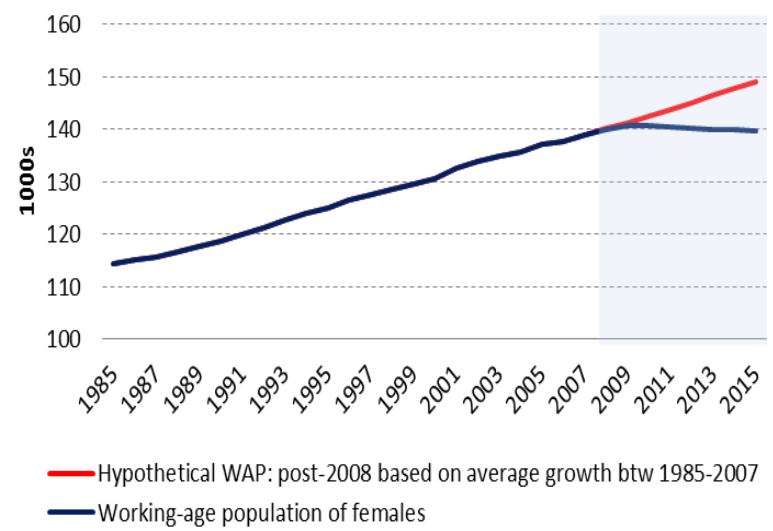

Figure 6. Trends in working-age population and labour supply of females

\subsection{Cohort Model of Labour Force Participation}

The second method is based on a cohort model of labour force participation. The female participation rate can be decomposed into the weighted sum of the participation rate of different demographic groups:

$$
P R_{t}=\sum_{i} s_{t}^{i} P R_{t}^{i}
$$

where $P R_{t}^{i}$ is the participation rate of group $i, s_{t}^{i}$ is the population share of group $i$ (i.e. $s_{t}^{i} \equiv \frac{P o p_{t}^{i}}{\operatorname{Pop}_{t}}$ ) and $P o p_{t}^{i}$ is the population of group $i$.

Over the past decade, there were changes in both the demographic composition of the female population and the participation rates by age bracket. The population share of the 25-39 age cohort has remained broadly unchanged over the past decade at around 25\% of the population aged 15 and above. The shares of the 15-24, 40-49 and 50-59 brackets have declined, with the drop being mostly pronounced for the first two categories. On the contrary, the share of older persons has increased, especially for those above 65 years, with the increase being especially pronounced from 2009 .

Notable changes were also observed in the participation rate of different age groups. As shown in figure 2 above, increases were registered in the participation rate of all cohorts above 25 years of age while the participation rate of teenagers and young adults has been declining. The latter phenomenon is also observed in almost all EU countries and is due to more young people opting to pursue further their education.

Following Kudlyak (2013), we conduct three different counterfactual exercises to understand the importance of changes in the labour force participation rates of different demographic and educational groups. In the first simulation, the female participation is kept fixed at its 2007 level and we allow the demographic composition of the population to follow its actual path. In the second exercise, the participation rate for the three different education categories is kept unchanged at their 2007 levels and we allow the demographic composition by education levels to follow their actual path. The third simulation fixes the female participation rate for the low and medium education at the 2007 levels but allows both the demographic composition by education and the participation rate of those with a tertiary level of education to follow their actual paths. The results of these counterfactual exercises are shown in chart 8. 


\section{Counterfactual simulations from cohort models}

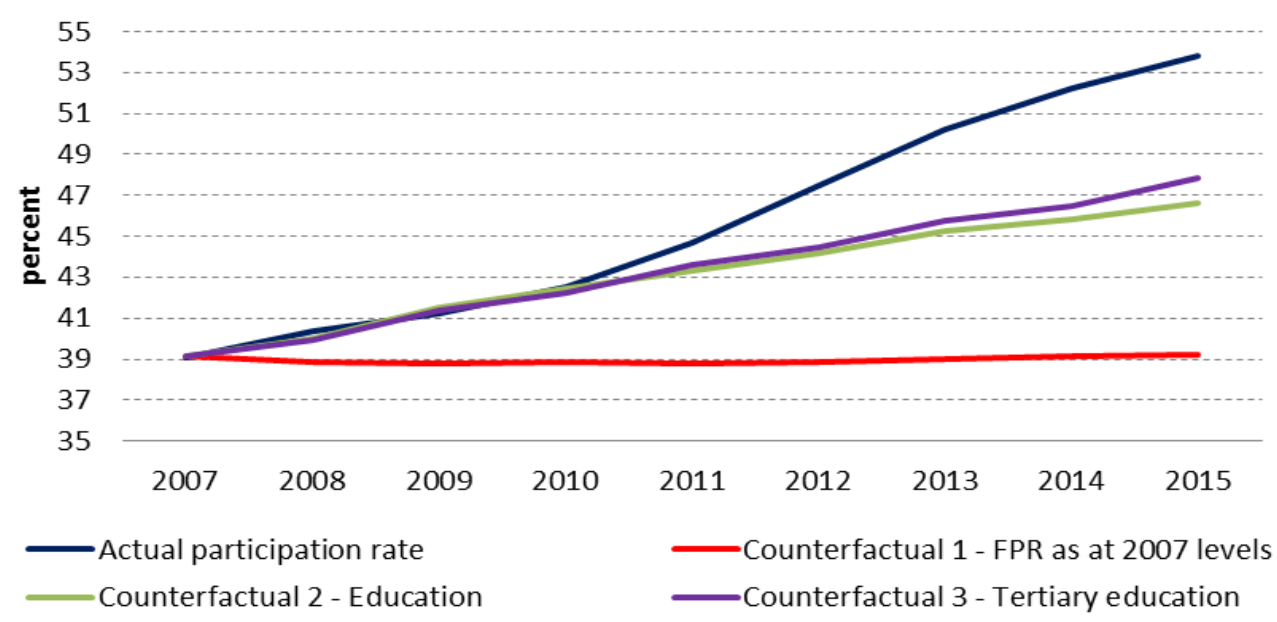

Figure 7. Counterfactual simulations from cohort models

The simulations point to different results. The hypothetical participation rate from the first simulation, in which the participation rate was kept fixed at the level prevailing in 2007, remained broadly unchanged. This is because the share of the largest age cohort (25-39) has remained broadly unchanged since 2008, while the decline in the other age brackets were offset by the increase in the older category. On the contrary, the other two simulations point to increases in the participation rate due to the upward trend in the share of the population with medium and high level of education and a corresponding drop of those with only a primary or lower secondary education. The latter two simulations are however not enough to explain the increase in the female participation rate observed since 2008. Higher education attainment raises the hypothetical participation rate to $47 \%$ - $48 \%$ by 2015, around 6 to 7 percentage points lower than the actual participation rate of $53.8 \%$. In addition, the gap between the actual and hypothetical participation rate started to widen significantly from 2011 indicating that demographic and education changes in the female population on their own are not enough to explain the sharp increase observed in the female participation rate in Malta.

\subsection{Impact of Reforms}

The two methods outlined in sections 5.1 and 5.2 point to a positive impact of labour market reforms on Malta's female participation rate in recent years. Calculating the precise impact of reforms, however, is challenging and surrounded by a degree of uncertainty since different methods provide different estimates. The fact that the reforms consist of various measures that were introduced gradually over a number of years makes this task even more difficult.

Figure 8 compares the unadjusted increase in the female participation rate and the estimated contribution of the reforms according to the different approaches outlined. The first method, described in section 5.1, adjusts both the working-age population and the labour supply of females post-2008 to the trends prevailing between 1985 and 2007. According to this method, the increase in the participation rate due to reforms amounted to around 4.3 percentage points since 2008 . The second method is based on a cohort model of the participation rate that accounts to changes in the demographic composition and the education attainment of the female population. According to these models, the impact of reforms on the participation rate since 2008 stood between 6.1 and 8.4 percentage points. 


\section{Impact of labour market reforms}

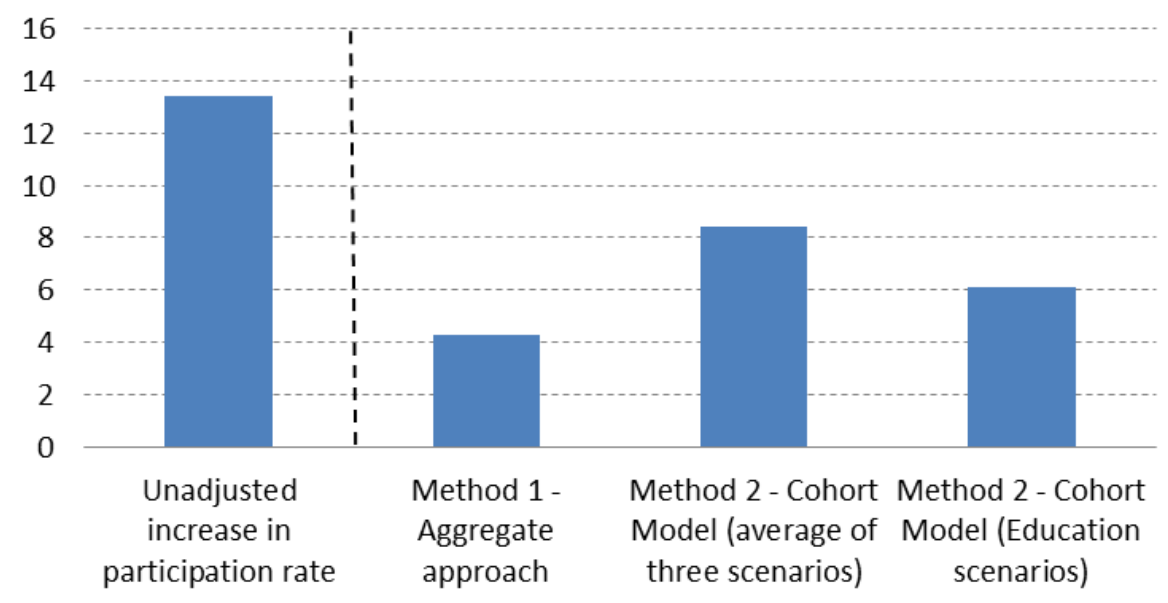

Figure 8. Impact of reforms on the female participation rate between 2008 and 2015

Table 2 summarizes the main results. Taking the median of the three approaches in Figure 8, slightly less than half of the 13.4 percentage point increase in the female participation rate between 2008 and 2015 is attributable to labour market reforms. Estimates from the production function approach in section 3 suggest that the increase in the participation rate contributed on average to 0.8 percentage points per annum to potential GDP in Malta between 2008 and 2015. The latter however includes the effect of both genders. Females accounted for around $75 \%$ of the increase in the employment during this period. Combining all these effects, the impact of the various labour market reforms to increase the female participation rate is calculated to have raised the economy's potential GDP growth by 0.3 percentage points per annum since 2008.

Table 2. Estimates of labour market reforms on potential output growth

\begin{tabular}{llc}
\hline & (percentage points) \\
\hline Increase in participation rate between 2008 and 2015 & & \\
Increase in participation rate between 2008 and 2015 due to reforms (taking the average from the 3 approaches in & & \\
chart 9) & & \\
Average contribution of participation rate to potential output growth between 2008 and 2015 & 0.3 \\
Impact on potential output attributable to reforms (47\%) and females (75\% of the increase in employment) & 0.3 \\
\hline 6. Conclusion
\end{tabular}

\section{Conclusion}

Albeit starting from a low level, Malta registered the largest increase in the female participation rate among EU countries since 2008. The estimates presented by this paper suggests that around half of the increase in the female participation rate since 2008 was due to the impact of reforms, which in turn, have boosted potential GDP by around 0.3 percentage points per annum.

The reform package enacted by the authorities, ranging from tax incentives to higher public expenditure on childcare, should continue to have positive effects on the female participation rate. These reforms should complement the other trends in Maltese society, such as higher education, lower fertility and the changing role of women in society, as well as more flexible work practices and the structural shift towards the services sector, which increases the demand for female work, all of which should continue to boost the female participation rate.

The increase in the female participation rate has been the main contributor to the gradual narrowing of the gap in income levels between Malta and the rest of the EU countries since the crisis. Furthermore, despite the large increases observed in recent years, the female participation rate in Malta still remains relatively low by European standards, thus providing additional catching-up potential in the future. That said, in the context of an ageing population, the future convergence prospects of the Maltese cannot rely solely on labour utilization but increasingly on labour productivity. This will require considerable investment to raise the education attainment of the Maltese workforce and to make sure that existing skill mismatches are addressed quickly.

\section{Acknowledgements}

The author would like to thank Aaron G Grech for helpful comments and suggestions. Any errors, as well as the views expressed in this paper, are the author's sole responsibility. 


\section{References}

Albanesi, S., \& Olivetti, C. (2007). Gender roles and medical progress, National Bureau of Economic Research, NBER Working Paper No. 14873.

Becker, G. (1965). A theory of the allocation of time, The Economic Journal, 75(299), $493-517$. https://doi.org/10.2307/2228949

Bick, A., \& Fuchs-Schündeln, N. (2014). Taxation and labor supply of married couples across countries: a macroeconomic analysis, C.E.P.R. Discussion Papers, No 9115.

Blanchard, O. (2004). The economic future of Europe, Journal of Economic Perspectives, 18, 3-26. https://doi.org/10.1257/0895330042632735

Bugeja, S., Mifsud, G., \& Saliba, P. (2016). Research Note: Illustrating the distributional implications of measures from the 2016 Budget for Malta, EUROMOD Working Paper series, EM12/16, December 2016.

Card, D., \& Krueger, A. (1994). Minimum wages and employment: A case study of the fast-food industry in New jersey and Pennsylvania, American Economic Review, 84(4), 772-793.

Christiansen, L., Lin, H., Pereira, J., Topalova, P., \& Turk, R. (2016). Individual choice or policies: drivers of female employment in Europe, IMF Working Paper WP/16/49.

Darmanin, M. (1992). The labour market of schooling: Maltese girls in education and economic planning, In: Gender and Education, 4(1/2), 105-126. https://doi.org/10.1080/0954025920040108

Eckstein, Z., \& Lifshitz, O. (2011). Dynamic female labor supply, Econometrica, 79(6), 1675-1726. https://doi.org/10.3982/ECTA8803

Edin, P., \& Gustavsson, M. (2008). Time out of work and skill depreciation, Industrial and Labor Relations Review, Cornell University, ILR School, 61(2), 163-180.

Fernández, R. (2013). Cultural change as learning: the evolution of female labor force participation over a century, American Economic Review, 103(1), 472-500. https://doi.org/10.1257/aer.103.1.472

Grech, A. G. (2015a). 'The evolution of the Maltese economy since Independence', Central Bank of Malta Working Paper $\mathrm{WP} / 05 / 2015$.

Grech, A. G. (2015b). 'The diversification of the Maltese economy', Central Bank of Malta Policy Note, August 2015.

Grech, A. G., \& Micallef, B. (2016). Assessing the supply side of the Maltese economy using a production function approach, in Understanding the Maltese Economy, Central Bank of Malta publication edited by A. G. Grech, 2016, pp. 37-44.

Grech, A. G., Micallef, B., a\& Zerafa, S. (2016). Diversification and structural change in the Maltese economy, in Understanding the Maltese Economy, Central Bank of Malta publication edited by A. G. Grech, 2016, pp. 15-24.

Jaumotte, F. (2003). Female labor force participation: past trends and main determinants in OECD countries, OECD Working Paper, ECO/WKP(2003)30.

Keane, M. (2011). Labor supply and taxes: a survey, Journal of Economic Literature, 49, $961-1075$. https://doi.org/10.1257/jel.49.4.961

Kudlyak, M. (2013). A cohort model of labour force participation, Federal Reserve of Richmond Economic Quarterly, 99(1), First Quarter 2013

McGinn, K., Lingo, E. L., \& Castro, M. R. (2015). Mums the World! Cross-national effects of maternal employment on gender inequalities at work and at home, Harvard Business School, Working Paper 15-094.

Micallef, B. (2013). Labour market resilience in Malta, box published in Central Bank of Malta Quarterly Review, 1.

Micallef, B. (2017). Empirical estimates of Okun's Law in Malta, Applied Economics and Finance, 4(1), 138-148

Ministry for Finance (2015). Malta National Reform Programme, available on: http://ec.europa.eu/europe2020/europe-2020-in-your-country/malta/national-reform-programme/index_en.htm

Pissarides, C., Garibaldi, P., Olivetti, C., Petrongolo, B., \& Wasmer, E. (2005). Women in the labour force: how well is Europe doing?” In: Boeri, T., Del Boca, D., Pissarides, C. (Eds.), European Women at Work. Oxford University Press.

Steinberg, C., \& Nakane, M. (2012). Can women save Japan?, IMF Working Paper WP/12/248.

Thévenon, O. (2013). Drivers of female labour force participation in the OECD, OECD Social, Employment and 
Migration Working Papers, No. 145.

Varga, J., \& in't Veld, J. (2014). The potential growth impact of structural reforms in the EU: a benchmarking exercise, European Economy Economic Papers, No. 541.

\section{Copyrights}

Copyright for this article is retained by the author(s), with first publication rights granted to the journal.

This is an open-access article distributed under the terms and conditions of the Creative Commons Attribution license which permits unrestricted use, distribution, and reproduction in any medium, provided the original work is properly cited. 